\title{
The Management of Unplanned Erection during Endoscopic Urological Surgery
}

\author{
Martin Gray ${ }^{\mathrm{a}} \quad$ Nikhil Vasdev $^{\mathrm{b}} \quad$ Shan Gowrie-Mohan ${ }^{\mathrm{a}} \quad$ Tom McNicholas $^{\mathrm{b}}$ \\ Department of anesthesia and ${ }^{b}$ Urological Surgery, Lister Hospital, Stevenage, UK
}

\section{Key Words}

Erection • Endoscopy • Ephedrine

\begin{abstract}
Penile erection at the time of urological surgery is a rare but problematic event which can delay, complicate or even lead to the cancellation of planned surgery. Erection may occur irrespective of the type of anesthetic method employed. Several techniques for treatment of this troublesome complication have been described in the literature, all with varying levels of success and potential adverse effects. In our experience over the last 25 years, we have found that intracavernous injection of ephedrine into the penis has a $100 \%$ success rate in safely producing detumescence with minimum side effects and should therefore be considered early among the treatment options for this condition.
\end{abstract}

Copyright $\odot 2016$ S. Karger AG, Basel

\section{Introduction}

Penile erection, or tumescence, is a rare but troublesome complication of endoscopic urological surgery, most commonly occurring following local stimulation of the penis during skin preparation or introducing the cystoscope or resectoscope [1]. The reported incidence is between 0.1 and $2.4 \%[1,2]$ and will lead to delay in the surgical procedure or possibly cancellation of the sur-

\section{KARGER}

Fax +4161306 1234

E-Mail karger@karger.ch

www.karger.com
(C) 2016 S. Karger AG, Basel

Accessible online at: www.karger.com/cur gery, or delay of other planned surgery. In rare cases the tumescence can prevent the surgeon from safely reaching the prostate or bladder. Although extra-long resectoscope sheaths are manufactured, they are rarely available in practice. Furthermore, transurethral surgery during penile tumescence may be associated with a greater risk of complications such as bleeding and stricture formation [3]. Surgery in such circumstances has medico-legal implications.

\section{Erection - The Process/Control}

The penis is innervated by both autonomic and somatic nerves. Penile blood vessels and corpus cavernosum smooth muscle receive rich adrenergic innervation via the sympathetic pathways originating from $\mathrm{T} 10$ to L2 before passing through the white rami to the sympathetic chain. Tonic activation of alpha-adrenoceptors in the penile vasculature and smooth muscle of the corpus cavernosum initiate the cascade which results in elevation of intracellular calcium levels and thus smooth muscle contraction and maintenance of the penis in the flaccid state [4]. The endothelin vasoconstrictors, synthesized and released locally from the endothelium, contribute to maintenance of smooth muscle contractility $[5,6]$.

Hence, alpha-adrenoceptors play a critical role in initiating and maintaining penile flaccidity. Indeed, systemic administration of alpha-adrenoceptor antagonists is known to facilitate penile erection or priapism [7-9].

Tom McNicholas

East \& North Herts NHS Trust, Lister Hospital

Corey's Mill Lane, Stevenage, Herts SG1 4AB

Stevenage (UK)

E-Mailmcnta@me.com 
The parasympathetic pathways supplying the penis arise from $\mathrm{S} 2$ to $\mathrm{S} 4$. The pre-ganglionic fibres pass to the pelvic plexus where they are joined by sympathetic fibres from the superior hypogastric plexus. The cavernous nerves are branches of the pelvic plexus which innervate the penis.

Parasympathetically mediated stimulation of the pelvic plexus and cavernous nerves results in a fall in free cytosolic calcium levels, and inflow of blood to the penis, with nitric oxide considered to have a central role in this process. The fall in free cytosolic calcium levels, coupled with compression/occlusion of venous outflow, is responsible for achieving and maintaining erection. Arterial flow also increases in the corpus spongiosum and glans but the pressure inside these areas of the penis only reaches about one third to a half that of the pressure within the cavernosa because the thin tunical covering of these regions only allows minimal venous occlusion (fig.1) [4].

Hence, sacral parasympathetic input is responsible for tumescence and thoracolumbar sympathetic pathways are responsible for detumescence [4].

Erection can be induced either psychogenically, centrally initiated from the brain via the spinal cord, or reflexogenically. Reflexogenic erection is produced by tactile stimulation to the genitalia. The impulses pass to the spinal erection centres, some following the ascending tracts thereby resulting in sensory perception, but others activate the autonomic nuclei and induce erection through stimulation of the cavernous nerves.

Reflexogenic erection is preserved in $95 \%$ of patients who have complete upper cord lesions, whereas only $25 \%$ of those who have complete lower cord lesions can achieve an erection [4], demonstrating that intact sacral parasympathetic neurons are important in the preservation of reflexogenic erection.

Interestingly males with a sacral spinal cord injury may retain the ability to induce a psychogenic erection even though the ability to induce a refloxogenic erection is abolished; that said, these erections tend to be suboptimal in that, despite penile swelling, insufficient rigidity is observed [4].

\section{Erection under Anesthesia}

The exact mechanism of erection at the time of surgery is unclear. As discussed, variations in tone of the smooth muscles of the corpus cavernosum are controlled by the autonomic nervous system. Sympathetic output from the low thoracic and higher lumbar spinal segments may be lost during regional or general anaesthesia. Local stimulation of the penis at the time of surgery would appear to activate sacral parasympathetic pathways and thereby instigate an unopposed reflex response via an autonomic imbalance [10]. Indeed, erections have been reported more commonly with blocks reaching higher than T8 and rarely with those lower than T12 [11]. However, this simple imbalance between autonomic input is undoubtedly an over simplification of the mechanism responsible for penile erection under anaesthesia as many other non -adrenergic, non-cholinergic and local transmitters are involved, and this may go some way to explain why the condition is not seen more commonly [12].

Penile tumescence at the time of surgery has been described irrespective of the type of anesthetic technique used. The overall incidence under anesthesia has been reported as being between 0.1 and $2.4 \%$ with predominance for younger males $[1,2,10]$. With an incidence of $0.34 \%$ for general anesthesia (GA), $1.72 \%$ for epidural and $0.11 \%$ for spinal in one paper [10] and 3.5\% GA, 3.8\% epidural and $0.3 \%$ for spinals in another [1], it would appear that the type of anesthetic technique may have an impact on how frequently this complication is observed.

The reason for an increased occurrence of erection under GA and epidural anaesthesia, when compared to spinal anaesthesia, is unclear. Furthermore, depth of GA does not appear to have any impact of the incidence [1], and deepening anesthesia is not an effective treatment when erection has occurred.

It is suggested that penile erection under GA is both psychogenic and refloxogenic in its mode of stimulation [13]. With the psychogenic stimulation arising from heighted sensory input or dreams under anesthesia [14] and the reflexogenic stumuli arising, as previously described, from sacral root afferents stimulated by washing, touching and instrumentation of the genital area.

Some medications have been implicated in a higher incidence of penile erection under GA. Indeed, probably the two most commonly used drugs for induction of anesthesia, namely fentanyl and propofol, have both been proposed to cause a higher incidence of erection under GA [15-17].

\section{Treatments}

There are several physical techniques described for management of this condition, each with varying levels of success. Reduction of sensory input to the penis 


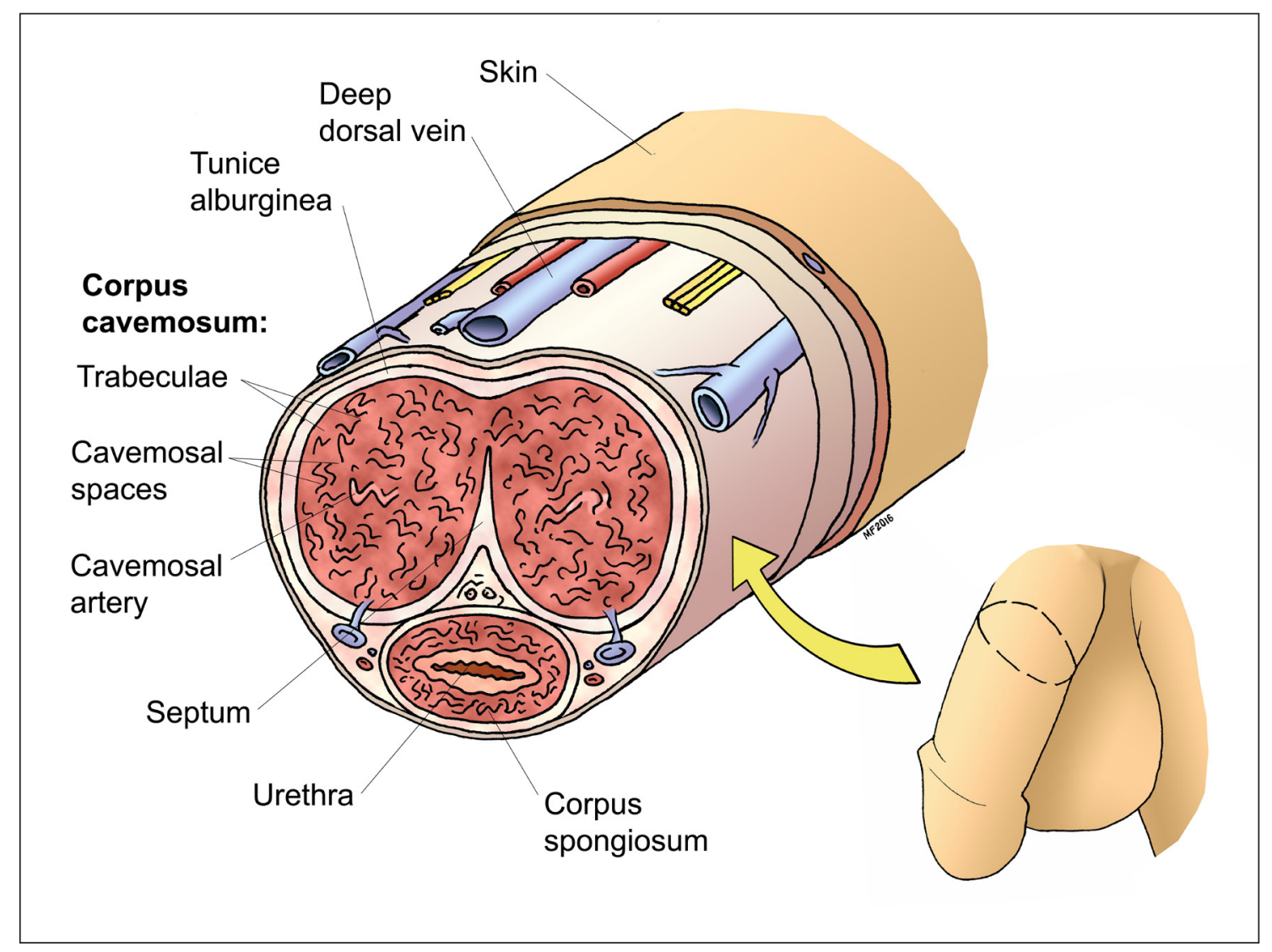

Fig. 1. Transverse section through the penis demonstrating relevant anatomy.

through the use of ethyl chloride or dorsal nerve block has been described as methods for avoiding intraoperative erection [18, 19]. Furthermore, dorsal nerve block has also been described as a treatment for established penile erection, with interruption of the sacral reflex arc through blockade of the afferents to the spinal cord proposed as the mechanism of action [11].

Many pharmacological treatments for intraoperative penile erection have also been suggested. These include intracavernous injection of phenylephrine, noradrenaline, adrenaline and metaraminol [20-23]; alternatively intravenous injection of ketamine [15, 24-28], glycopyrrolate [29], terbutaline [13, 19] and dexmedetomidine [10] has been suggested. Even bronchial administration of salbutamol has been reported as having some level of success in treating this condition [16]. Worryingly, adverse events and even death have been described following some of these treatments especially following administration of the more powerful vasoactive agents $[2,30]$.

The Management of Unplanned Erection during Endoscopic Urological Surgery
The fact that so many agents and techniques have been suggested in the literature demonstrates that no single method of treating this problematic situation is fully effective or without side effects. Intracavernous injection of vasoactive agents may cause local effects such as pain, hematoma, infection and fibrosis $[13,16]$, but more worryingly, they may lead to systemic uptake, and have induced hypertensive crisis, pulmonary edema and have even resulted in mortality [2, 30, 31].

Intravenous ketamine has been a popular choice for management of this condition but one major disadvantage of this treatment is the time to achieve flaccidity, which may take 90 minutes to 2 hours $[25,26]$. The patient may also suffer all the other side effects associated with ketamine usage including hallucinations and unpleasant dreams.

Intravenous terbutaline should be used with caution due to the risk of tachycardia, pulmonary edema and hypokalemia associated with use of this drug [32]. 
More recently, intravenous dexmedetomidine has been suggested as a treatment in this situation, demonstrating detumescence in $83 \%$. A statistically significant reduction in heart rates and systolic blood pressure was associated with its use; however no corrective treatment was required/utilised in the sample [10].

\section{Ephedrine Injection}

In our experience the technique of choice is now intracavernosal injection of ephedrine. We have progressed from initially using intracavernosal phenylephrine [33] to intracavernosal injection of ephedrine [34, 35]. Over the last 25 years we have found this technique to be routinely successful in treating this condition and, with the exception of minor bruising of the penis, have experienced no adverse outcomes for patients. There are obvious advantages of using an agent which is familiar to those working in the theater environment. Ephedrine is frequently used for cardiovascular manipulation by most anesthetists and it is routinely immediately available in a form that does not require potentially error-prone dilution.

\section{Technique}

In most circumstances the endoscope should be removed from the urethra. Ephedrine, $30 \mathrm{mg}$ in $1 \mathrm{ml}$ solution, is drawn up undiluted in a $1 \mathrm{ml}$ syringe before attaching a $23 \mathrm{G}$ (orange) needle. Half $(0.5 \mathrm{ml})$ of the solution is injected into one of the cavernosal bodies. The drug is then massaged throughout the penis. We recommend firm pressure over the injection site to reduce, and usually avoid, penile bruising. It is unusual to need the remainder of the drug but it can be injected, preferably at another penile site, if erection persists or recurs. The action is rapid and detumescence is achieved almost immediately.

Clearly, injection of this sympathomimetic amine could be associated with adverse effects, the most obvious being a rise in systemic blood pressure. Consequently, agreement must be sought from the anesthetist prior to intracavernosal injection of ephedrine.

In common with the administration of any medication, prior to injection one must consider the patient's current health status, their co-morbidities, and which other drugs have recently been administered, in order to minimize the chance of an adverse effect. Furthermore, following intracavernosal injection the patient should be closely monitored, including frequent blood pressure measurements, for at least the following hour. All necessary agents to deal with any hypertensive episode or arrhythmia should also be immediately available to the anesthetist; however, such agents should always be routinely available wherever an anesthetic is being undertaken.

\section{Summary}

Intraoperative penile erection at the time of urological surgery is a rare but problematic complication which can delay or even lead to the cancellation of surgery. We believe that intracavernosal injection of ephedrine should be considered early amongst the published list of potential treatments of this troublesome complication. In our experience, over the last 25 years, we have found this agent to be both safe and effective. There are obvious advantages of using an agent which is familiar to those working in the theater environment. The drug is frequently used for cardiovascular manipulation by most anesthetists and it is routinely immediately available in a form that does not require potentially error-prone dilution. 


\section{References}

1 Staerman F, Nouri M, Coeurdacier P, Cipolla B, Guille F, Lobel B: Treatment of the intraoperative penile erection with intracavernous phenylephrine. J Urol 1995;153:1478-1481.

2 Blandy JP: Transurethral surgery; in Blandy JP, Lytton B (eds): The Prostate. London, Butterworth, 1986, pp58-59.

3 Baltogiannis DM, Charalabopoulos AK, Giannakopoulos XK, Giannakis DJ, Sofikitis NV, Charalabopoulos KA: Penile erection during transurethral surgery. J Androl 2006; 27:376-380.

4 Dean RC, Lue TF: Physiology of penile erection and pathophysiology of erectile dysfunction. Urol Clin North Am 2005;32:379-395.

5 Traish A, Kim NN, Moreland RB, Goldstein I: Role of alpha adrenergic receptors in erectile function. Int J Impot Res 2000;12(suppl 1):S48-S63.

6 Andersson KE: Erectile physiological and pathophysiological pathways involved in erectile dysfunction. J Urol 2003;170:S6S14.

7 Brindley GS: Cavernosal alpha-blockade: a new technique for investigating and treating erectile impotence. Br J Psychiatry 1983;143: 332-227.

8 Blum MD, Bahnson RR, Porter TN, Carter MF: Effect of local alpha-adrenergic blockade on human penile erection. J Urol 1985; 134:479-481.

9 Zorgniotti AW: Experience with buccal phentolamine mesylate for importence. Int J Impot Res 1994;6:37-41.

10 Guler G, Sofikerim M, Ugur F, Aksu R, Boyaci A: Intravenous dexmedetomidine for treatment of intraoperative penile erection. Int Urol Nephrol 2012;44:353-357.

11 Pertek JP, Coissard A, Artis M: Dorsal nerve block for intraoperative management of penile erection. Reg Anesth 1996;21:491-492.
12 Kouriefs C, Watkin NA: What to do if it gets 'bigger'. Ann R Coll Surg Engl 2003;85:126128.

13 Shantha TR: Intraoperative management of penile erection by using terbutaline. Anesthesiology 1989;70:707-709.

14 Weiss HD: The physiology of human penile erection. Ann Intern Med 1972;76:793-799.

15 Roy R: Cardiovascular effects of ketamine given to relieve penile turgescence after high doses of fentanyl. Anesthesiology 1984;61: 610-613.

16 Prakash S, Sharm S, Miglani S, Gogia AR: Management of intraoperative penile erection with salbutamol aerosol. J Anaesthesiol Clin Pharmacol 2012;28:402-403.

17 Vesta KS, Martina SD, Kozlowski EA: Propofol-induced priapism, a case confirmed with rechallenge. Ann Pharmacother 2006;40: 980-982.

18 Miller PD, Galizia EJ: Management of erections during transurethral surgery using ethyl chloride spray. Br J Urol 1993;71:105.

19 Seftel AD, Resnick MI, Boswell MV: Dorsal nerve block for management of intraoperative penile erection. J Urol 1994;151:394-395.

20 Siegel JF, Reda E: Intracorporeal phenylephrine reduces thioridazine (Mellaril) induced priapism in a child. J Urol 1997;157: 648.

21 de Meyer JM, De Sy WA: Intracavernous injection of noradrenaline to interrupt erections during surgical interventions. Eur Urol 1986; 12:169-170.

22 Zappala SM, Howard PJ, Hopkins TB, Blute RD: Management of intraoperative penile erections with diluted epinephrine solution. Urology 1992;40:76-77.

23 Tsai SK, Hong CY: Intracavernosal metaraminol for treatment of intraoperative penile erection. Postgrad Med J 1990:66:831-833.
24 Villalonga A, Beltran J, Gomar C, Nalda MA: Ketamine for treatment of priapism. Anesth Analg 1985;64:1033-1034.

25 Ravindran RS, Dryden GE, Somerville GM: Treatment of priapism with ketamine and physostigmine. Anesth Analg 1982;61:705707.

26 Benzon HT, Leventhal JB, Ovassapian A: Ketamine treatment of penile erection in the operating room. Anesthesia Analgesia 1983; 62:457-458.

27 van Arsdalen KN, Chen JW, Smith MJ: Penile erection complicating transurethral surgery. J Urol 1983;129:374-386.

28 Gale AS: Ketamine prevention of penile turgescence. JAMA 1972;219:1629.

29 Valley MA, Sang CN: Use of glycopyrrolate to treat intraoperative penile erection: case report and review of the literature. Reg Anesth 1994;19:423-428.

30 Maan Z, Arya M, Patel HR: Priapism - a review of the medical management. Expert Opin Pharmacother 2003;4:2271-2277.

31 Lue TF: Editorial comment. J Urol 1988;139: 737.

32 Shantha TR, Finnerty DP, Rodriguez AP: Treatment of persistent penile erection and priapism using terbutaline. J Urol 1989;141: 1427-1429.

33 McNicholas TA, Thomson K, Rogers HS, Blandy JP: Pharmacological management of erections during transurethral surgery. $\mathrm{Br} \mathrm{J}$ Urol 1989;64:435-436.

34 Sundien E, Kolmert T: Ephedrine: a possible alternative for treatment of penile erection in connection with transurethral resection of prostatic or bladder tumours. J Urol 1987; 138:411.

35 McNicholas T: Re: Pharmacological management of erections during transurethral surgery. Br J Urol 1990;66:219-220. 